\title{
Effect of methanolic extracts of Tectona grandis linn leaves on diabetic neuropathy in streptozotocin- induced diabetic rats
}

\begin{abstract}
Tectona grandis (TG) plant belonging to family Verbenaceae, it is medicinally reported and claims to cure various diseases in Indian traditional system (Ayurveda) and in folklore. The purpose of this study is to examine the methanol extract of Tectona grandis leaves (TGME) in Streptozotocin (STZ) induced diabetic neuropathy in rat. Initially acute oral toxicity study of TGME was carried out in rats to evaluate the dose for animal study. STZ (45 mg. $\mathrm{kg}^{-1}$ ) was used to induce diabetes in rats. TGME was given orally dose of 250 and $500 \mathrm{mg} . \mathrm{kg}^{-1}$ to normal and diabetic rats from initiate $7^{\text {th }}$ to $8^{\text {th }}$ weeks (total 14 days). Blood collection for estimation of glucose level, biochemical parameters and behavioural parameters were assessed initially up to $8^{\text {th }}$ week (every $2^{\text {nd }}$ week interval). At the end of study (after $8^{\text {th }}$ week) rats were sacrificed for estimation brain tissue estimations and histopathology of rat paw skin was also carried out. In acute oral toxicity study result, TGME do not cause any toxicity or death in animals. Diabetic rat's significant increase in serum glucose and other biochemical parameters as well as mechanical allodynia was indicates hyperalgesia after 2 weeks of diabetes induction. Brain tissue estimations revealed increase in lipid peroxidation (LPO) level, a decrease in antioxidant parameters and histopathology study of paw skins of rat's intraepidermal nerve fiber density was decreased in diabetic neuropathy STZ treated group. Administration of dose of 250 and $500 \mathrm{mg}$. $\mathrm{kg}^{-1}$ of TGME significantly $(\mathrm{P}<0.001)$ decreased blood glucose level in normal and diabetic rats. A dose of $500 \mathrm{mg} . \mathrm{kg}-1$ significantly $(\mathrm{P}<0.01$ and $\mathrm{P}<0.001)$ increases the tail withdrawal latency with hot and cold water tail immersion tests respectively. Both the doses of TGME significantly increase the level of glutathione (GSH) and lower the levels of LPO, catalase (CAT) and superoxide dismutase (SOD). Histopathology study of paw skin of rat intraepidermal nerve fiber density was increased as a result of drug administration. The results concluded that TGME possesses potential to combat glucose; hypolipidemic effect and scavenge free radicals in diseases associated with oxidative stress, suggests its role in preventing diabetes-related complications.
\end{abstract}

Keywords: Tectona grandis, diabetes mellitus, peripheral neuropathy, allodynia, hyperalgesia, oxidative stress
Volume 2 Issue 4 - 2018

\author{
Ajay Singh Kushwah,' Prminder Kaur,' \\ Thippeswamy Boreddy Shivanandappa ${ }^{2}$ \\ 'Department of Pharmacology,ASBASJS Memorial College of \\ Pharmacy, India \\ ${ }^{2}$ Department of Biomedical Science, College of Pharmacy for \\ Boys. Shaqra University, Al-Dawdmi Campus, Kingdom of Saudi \\ Arabia
}

Correspondence: Ajay Singh Kushwah, Department of Pharmacology, ASBASJS Memorial College of Pharmacy, India, Tel +919417459195, Email kushwah_ph05@yahoo.co.in

Received: June 12, 2018 | Published: July 13, 2018

\section{Introduction}

The prevalence of diabetes mellitus (DM) is rapidly increasing all over the globe at an alarming rate and it is now recognized as "silent epidemic". ${ }^{1}$ India leads the world with the largest number of diabetic subjects having a distinction of being termed the "diabetes capital of the world". ${ }^{2}$ Diabetic neuropathies (DN) are among the most frequent complications of DM affecting 50\% of the people with diabetes. DN is a heterogeneous group of conditions characterized by a progressive loss of nerve fiber function involving different components of the somatic and autonomic nervous systems. ${ }^{3}$ Possible causative factors include persistent hyperglycemia, oxidative stress-mediated nerve destruction which may lead to pain. ${ }^{4}$ The progression of DN increases with duration of diabetic hyperglycemia and it's inducing oxidative stress resulting activation of multiple pathways which can cause damage to the neurons alone or in combination. Despite its prominence in today's society, there is very little therapeutic strategy available to treat diabetes and its associated complications. The therapy available for diabetes such as insulin and other oral hypoglycemic agents is able to lower blood glucose level in different ways. These drugs also have certain adverse effects including hypoglycemia at higher doses, hepatotoxicity, lactic acidosis and diarrhea. The therapeutic implications available for $\mathrm{DN}$ are effective only for symptomatic relief. Since this complication can occur after 10-20years after diabetes and is present with foot ulcers and amputations, which are the only cause of hospital admissions. The primary goal of therapy is through improved glycemic control and prevents worsening of neuropathy. Various drugs have been used to treat painful symptoms, but only duloxetine and pregabalin possess FDA (Food and Drug Administration) approval for the treatment of painful peripheral diabetic neuropathy. ${ }^{5}$ Treatment medications limited because have high drug side effects, and no single drug is universally effective. Recently developing an approach for the treatment of diabetic neuropathy alternative therapeutic options by many herbal medicines have been recommended. Herbal drugs are prescribed widely because of fewer side effects and relatively low cost. ${ }^{6}$ Therefore, investigation of such agents from the traditional use of medicinal plants has become more important. India has a rich history of using various potent herbs and herbal components for treating diabetes and its complications. ${ }^{7}$ Plant Tectona grandis Linn. (TG) belongs to family Verbenaceae native to India, and it is found in the monsoon vegetation forest. It is commonly known as sagwan (Hindi), and teak tree (English). ${ }^{8}$ Phytoconstituents of TG present in various parts are Triterpenic hemiterpene compound, 
Lignins, Quinones, Phenolic acids and Flavonoids.9,10 Traditional and ethnopharmacological uses of TG are in the treatment of various disorders like anti-inflammatory, antioxidant and lipid disorders hypoglycemic, antidiabetic, and a diuretic. ${ }^{11}$ The literature review of the plant reported the presence of various phytoconstituents which are responsible for the different activities. The slight work has been done on the leaves of this plant, whereas maximum studies show that ethanolic extracts of bark and methanolic extract of root was used for the treatment of diabetes mellitus and produced a gradual but significant reduction in blood glucose level and leaves known to have tectone, a hypoglycemic constituent. In spite of the above activities leaves of the plant also possess analgesic and anti- oxidant activity was therefore thought to work on leaves of this plant need to explore as a potent drug to reverse diabetic neuropathy. In the present investigation, the methanolic extract of leaves of TG will be subjected to access its activity in diabetic neuropathy against Streptozotocin (STZ) induced diabetic rats. ${ }^{12-14}$

\section{Materials and methods}

\section{Collection of plant material, extraction, and pharmacognostic studies}

After selection of the plant TG collection from Patiala region, Punjab, India, and drying of leaves were done. Authentication of the plant was carried out from a voucher specimen no. 1458/Bot. \& Env. Sci. 1458/ Botany \& Environmental Science have been submitted to the herbarium of Department of Botanical and Environmental Sciences, Guru Nanak Dev University, Amritsar, Punjab, India. The leaves of TG were washed with running water in order to remove any dust impurities and dried under shade. They were powdered as coarse particles with a grinder and are extracted by the successive solvent method by using Soxhlet apparatus. The extracts were concentrated in a rotary evaporator (Heidolph, Germany) under reduced pressure. Preliminary phytochemical screening, antioxidant screening by using reducing power assay and 2, 2-Diphenyl-1-picrylhydrazyl (DPPH) assay of various extracts was reported. The extract having best antioxidant activity was choosing. This preliminary study already reported our past research publication on the basis of previous findings selected TGME best extract. ${ }^{15}$

\section{Acute toxicity study of leaves of Tectona grandis and dose selection}

An experiment was conducted to find whether an extract of leaves produces any toxic sign and dose selection on normal rats. Fifteen normal healthy rats starved for $12 \mathrm{~h}$ were randomly divided into five groups $(\mathrm{n}=3)$ and were administered orally with TGME starting with the dose of 5, 50, 300, 2000 and $5000 \mathrm{mg} \cdot \mathrm{kg}^{-1}$ body weight (b.w.). Animals were dosed individually and observed continuously for $8 \mathrm{~h}$ on the first day and thereafter for 14days their behavioural and neurological parameters were observed for a sign of acute toxicity; a dose of $2000 \mathrm{mg} \cdot \mathrm{kg}^{-1}$ was assessed according to the Organization for Economic Cooperation and Development (OECD) guidelines 423. On the basis of acute toxicity study, selection of 2 doses of the drug $\left(1 / 4^{\text {th }}\right.$ and $1 / 8^{\text {th }}$ ) was carried out. All rats were allowed to a standard pellet diet and tap water ad libitum, and the mortality caused by the extracts within this period of time was also observed.

\section{Experimental animals}

Adult fifty- one rats (either sex) of the Sprague Dawley strain weighing 200-260gm; between 8-10weeks of age kept in Central
Animal House Facility of ASBASJSM College of Pharmacy were used in this study. They were carefully maintained under the standard condition of temperature $25 \pm 5^{\circ} \mathrm{C}$, relative humidity $35-60 \%$ with $12 \mathrm{~h} \mathrm{light/dark} \mathrm{cycles.} \mathrm{All} \mathrm{experimental} \mathrm{animals} \mathrm{were} \mathrm{allowed} \mathrm{to}$ acclimatize laboratory ambiance for a period of one week, fed with standard pellet diet and purified water ad libitum, prior to the experiment as per the Committee for the Purpose of Control and Supervision of Experiments on Animals (CPCSEA) guideline. All experiment was carried out in according to guidelines and supervision of Institutional Animal Ethics Committee (IAEC) with approval no. ASCB/IAEC/03/11/054)

\section{Induction of diabetic neuropathy}

Diabetes was induced in the rats by single i.p. injection of STZ $45 \mathrm{mg} . \mathrm{kg}^{-1} \mathrm{~b}$.w. (procured from Sigma Aldrich USA) in freshly prepared cold citrate buffer ( $\mathrm{pH} 4.5$ ). In order to prevent fatal hypoglycemia due to massive pancreatic insulin release, rats were treated with $15 \%$ glucose solution bottles in their cages from $6^{\text {th }} \mathrm{hr}$ to a period of $24 \mathrm{~h}$. After $72 \mathrm{~h}$, the animals showing blood glucose level $250 \mathrm{mgdL}^{-1}$ were considered diabetic and are used for the study. ${ }^{16}$ Diabetic rats were kept under standard laboratory condition for the stabilization of blood glucose level during the period of study.

\section{Treatment and experiment protocol}

The rats were randomly divided in six groups $(n=6)$, Group 1: CNormal control (only saline treated); Group 2: STZ-Diabetic control (untreated); treated with $250 \mathrm{mg} \cdot \mathrm{kg}^{-1}$ b.w. of TGME; Group 6: DDT (H)-Diabetic rats treated with $500 \mathrm{mgkg}^{-1}$ b.w. of TGME. Methanolic extract of TG was dissolved in 2\% Carboxy Methyl Cellulose (CMC Group 3: ODT (L)-Normal rats treated with $250 \mathrm{mg} \cdot \mathrm{kg}^{-1}$ b.w. of TGME; Group 4: ODT (H)-Normal rats treated with $500 \mathrm{mg} . \mathrm{kg}^{-1} \mathrm{~b} . w$. of TGME; Group 5: DDT (L)-Diabetic rats, and selected dose levels administered p.o./daily to animals for 14 days (during $7^{\text {th }}$ to $8^{\text {th }}$ week). The dose was prepared freshly every day and given a dose of 250 and 500mg. $\mathrm{kg}^{-1}$ to normal as well as diabetic groups. Initially, at $48 \mathrm{~h}$ and then after $2^{\text {nd }}, 4^{\text {th }}, 6^{\text {th }}$, and $8^{\text {th }}$-week fasting serum glucose levels, lipid profile were estimated along with tail flick latency with cold and hot water tail immersion. At the end of the experiment, animals were sacrificed for the study of biochemical changes in serum and excision of brain tissue along with histopathology study of paw skin Figure1.

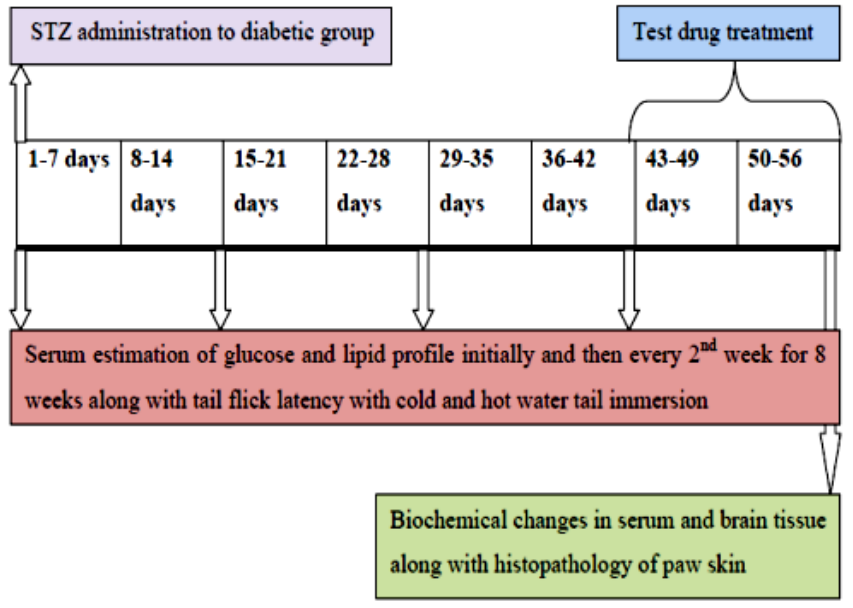

Figure I Flow diagram of experimental study protocol. 


\section{Preparation of serum sample and estimations of biochemical parameters}

The overnight fasted rats were taken for blood collection after $48 \mathrm{hrs}, 2^{\text {nd }}$ week, $4^{\text {th }}$ week, $6^{\text {th }}$ week and an $8^{\text {th }}$ week during the course of study in all rats. The blood was collected by puncturing retro-orbital plexus, under ether anesthesia and collected in non-heparinised Eppendorf tubes $(1.5 \mathrm{ml})$. Serum was separated by centrifugation at $3000 \mathrm{rpm}$ at $30^{\circ} \mathrm{C}$ for $15 \mathrm{~min}$ and utilized for the estimation of various biochemical parameters.

The serum glucose concentration was estimated (Microlab 300 bioanalyzer Merck) based on glucose oxidase-peroxidase (GODPOD) method; cholesterol and triglyceride concentration was estimated by using the commercially available kit (Merck Specialities Pvt. Ltd., Goa, India).

\section{Behavioral assessment of diabetic neuropathy (tail immersion- cold and hot water) test}

Tail withdrawal latency measurements were performed initially after $48 \mathrm{~h}$ of STZ treatment and then after every $2^{\text {nd }}$ weeks for $8^{\text {th }}$ weeks by tail immersion test in hot and cold water. Cold allodynia tail withdrawal latency $(\mathrm{sec})$ was measured by dipping the tail in water at a cold temp $\left(10 \pm 0.5^{\circ} \mathrm{C}\right)$ that is normally innocuous. The latency of tail withdrawal to cold stimulation was measured thrice, five min apart in each rat. A cut-off time of $12 \mathrm{sec}$ was taken and a decrease in tail withdrawal time indicates allodynia. ${ }^{17}, 18$ The hot water mean withdrawal latency of the rat tail measured by immersed in a hot water bath $\left(52.5 \pm 0.5^{\circ} \mathrm{C}\right)$ until tail withdrawal (flicking response) or signs of struggle were observed (cut-off $12 \mathrm{sec}$ ). ${ }^{18}$ The tail withdrawal latency was measured thrice, five min apart. Shortening of the tail withdrawal time indicates hyperalgesia.

\section{Preparation of brain homogenate and determination of antioxidant levels}

After collection of blood samples, the rats were sacrificed by decapitation and their brain excised, rinsed in ice- cold normal saline followed by $0.15 \mathrm{M}$ Tris- $\mathrm{HCl}(\mathrm{pH} 7.4)$ blotted dry and weighed. A $10 \% \mathrm{w} / \mathrm{v}$ of homogenate was prepared in $0.15 \mathrm{M}$ Tris- $\mathrm{HCl}$ buffer and processed for the estimation of lipid peroxidation (LPO)..$^{19}$ A part of homogenate after precipitating proteins with Trichloroacetic acid (TCA) was used for estimation of Glutathione (GSH) ${ }^{20}$ The rest of the homogenate was centrifuged at $15000 \mathrm{rpm}$ for $15 \mathrm{~min}$ at $4^{\circ} \mathrm{C}$. The supernatant thus obtained was used for the estimation of Super Oxide Dismutase (SOD) and Catalase (CAT) and also the estimate brain protein content. ${ }^{21-23}$

\section{Histopathological examination of the paw skin}

The animals were sacrificed; their intact skin was taken from the paw and was washed with ice-cold saline. Then the skin was dipped in air tight container containing formalin. The samples were sent to Sandhu pathology Lab., Sec 34A, Chandigarh for preparation of slides of skin. For interpretation, the pictures were taken from the prepared slides with the help of computer fitted microscope with camera (Motic).

\section{Statistical analysis}

All the data expressed as mean \pm SEM were evaluated by oneway analysis of variance (ANOVA), followed by Dunnet's test for multiple comparisons using Prism Graph Pad and values of $\mathrm{P}<0.05$ were considered as statistically significant.

\section{Results}

\section{Pharmacognostic and acute oral toxicity study of methanolic extract of Tectona grandis leaves (TGME)}

A preliminary phytochemical investigation revealed the presence of total phenolic, flavonoid content and in-vitro antioxidant screening by using reducing power assay and DPPH assay of methanolic extract of TG was found to be higher than other extracts. Study results already reported our past research publication. Acute oral toxicity studies (OECD guideline 423) revealed the non-toxic nature of the TGME. No lethality or toxic reaction found at any dose selected for the observation duration (14 days). No behavior changes appeared except moderate sedation occurs after $1 \mathrm{~h}$

\section{Effect of methanolic extract of Tectona grandis leaves (TGME) on serum biochemical parameters}

Hyperglycaemia in diabetic groups occurred $48 \mathrm{hrs}$ after STZ administration resulted in significant elevation $(\mathrm{P}<0.001)$ when compared to normal saline control group. Drug treatment for 14days during $7^{\text {th }}$ and $8^{\text {th }}$ week in normal rats significantly decrease $(\mathrm{P}<0.001)$ glucose level at a dose of 250 and $500 \mathrm{mg} \cdot \mathrm{kg}^{-1}$ b.w. respectively when compared with normal saline control group. Drug treatment to the diabetic group, during $7^{\text {th }}$ and $8^{\text {th }}$ week (for 14 days) of STZ administration showed that glucose level significantly decrease $(\mathrm{P}<0.001)$ as compared to diabetic control rats at both doses level Figure 2. Serum cholesterol level in STZ induced diabetic group rises after the first week but revealed that there was remarkably increase $(\mathrm{P}<0.001)$ on $6^{\text {th }}$ and $8^{\text {th }}$ week as compared to normal saline animals. However, administration of TGME for two weeks ( $7^{\text {th }}$ and $8^{\text {th }}$ week) to diabetic rats $\left(500 \mathrm{mg} \cdot \mathrm{kg}^{-1}\right.$ p.o. for 14 days) showed a significant reduction $(\mathrm{P}<0.001)$ in serum cholesterol level Figure 3. The level of triglyceride in serum increased significantly $(\mathrm{P}<0.001)$ after $48 \mathrm{hrs}$ in rats diabetes induced with STZ as compared to normal saline rats, and thereafter every week during the course of study. Supplement of the drug in normal animals during $7^{\text {th }}$ and $8^{\text {th }}$ week, (for continuous 14 days) resulted in a decrease $(\mathrm{P}<0.01)$ in triglyceride level at a dose of 500mg. $\mathrm{kg}^{-1}$ when compared to normal saline control group. Drug treatment with TGME at a dose of $500 \mathrm{mg} . \mathrm{kg}^{-1}$ p.o. to diabetic group resulted in significant decrease $(\mathrm{P}<0.05)$ in triglyceride level as compared to diabetic control group Figure 4.

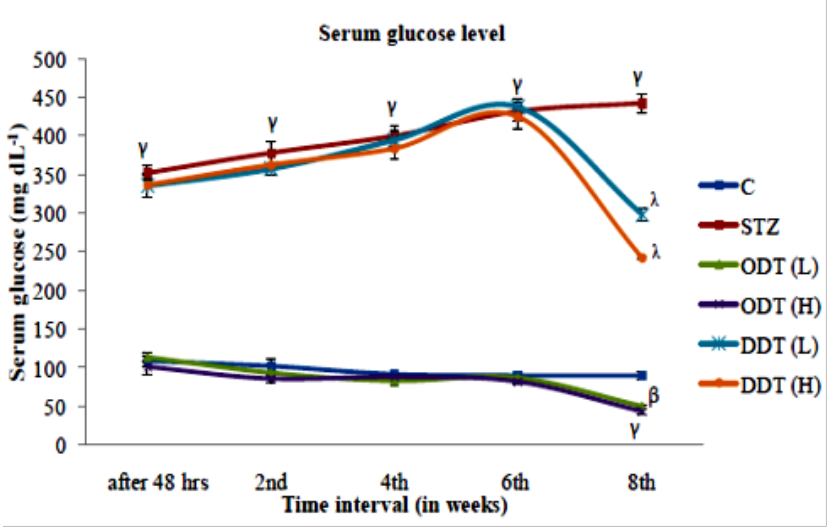

Figure 2 Effect of TGME at dose 250 and $500 \mathrm{mg} \cdot \mathrm{kg}^{-1}$ on serum glucose level in normal and diabetic rats. Values are expressed as Mean \pm SEM $(n=6),{ }^{\beta} \mathrm{P}<0.01$ $\gamma \mathrm{P}<0.00 \mathrm{I}, \mathrm{Vs}$ Normal control group, ${ }^{\lambda} \mathrm{P}<0.00$ I Vs Diabetic control group. One Way ANOVA followed by tukey's test for multiple comparisons. 


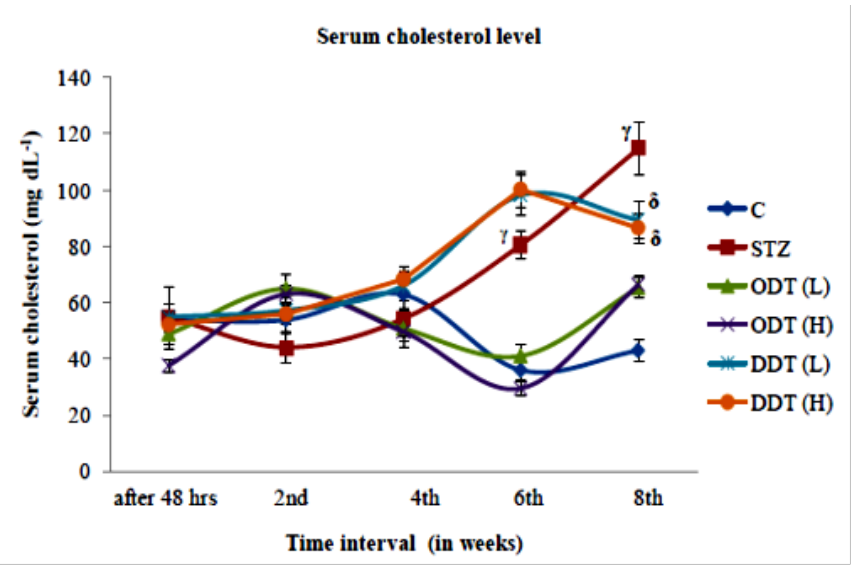

Figure 3 Effect of TGME at dose 250 and $500 \mathrm{mg} \cdot \mathrm{kg}^{-1}$ on serum cholesterol level in normal and diabetic rats. Values are expressed as Mean $\pm \operatorname{SEM}(n=6)$, $\gamma \mathrm{P}<0.00 \mathrm{I}$ Vs Normal control group, ${ }^{\delta} \mathrm{P}<0.05 \mathrm{Vs}$ Diabetic control group. One Way ANOVA followed by tukey's test for multiple comparisons.

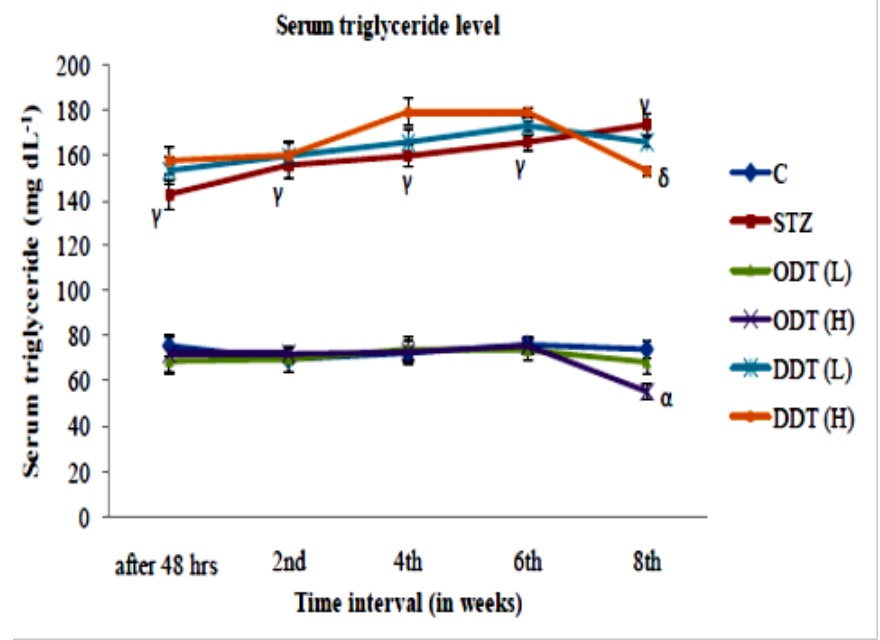

Figure 4 Effect of TGME at dose 250 and $500 \mathrm{mg} \cdot \mathrm{kg}^{-1}$ on serum triglyceride level in normal and diabetic rats. Values are expressed as Mean $\pm \operatorname{SEM}(n=6)$, ${ }^{\alpha} \mathrm{P}<0.05, \gamma \mathrm{P}<0.00 \mathrm{I}, \mathrm{Vs}$ Normal control group, ${ }^{\delta} \mathrm{P}<0.05 \mathrm{Vs}$ Diabetic control group. One Way ANOVA followed by tukey's test for multiple comparisons.

Effect of methanolic extract of Tectona grandis leaves (TGME) on behavioral assessment of diabetic neuropathy (Tail-immersion- cold and hot water) test

Cold water immersion test revealed that in the $2^{\text {nd }}$ and $4^{\text {th }}$-week significant reduction $(\mathrm{P}<0.01)$ in tail withdrawal latency or struggle occurred and a significant reduction $(\mathrm{P}<0.001)$ occurred during $6^{\text {th }}$ and $8^{\text {th }}$ week in STZ group as compared to normal saline control group. Diabetic rats supplemented with TGME $\left(500 \mathrm{mg} \cdot \mathrm{kg}^{-1}\right)$ for 14 days (during $7^{\text {th }}$ and $8^{\text {th }}$ week) resulted in significant increased $(\mathrm{P}<0.01)$ tail withdrawal latency as compared to diabetic group Figure 5. Hot water immersion test revealed significant reduction $(\mathrm{P}<0.01)$ in tail withdrawal latency in STZ induced diabetic group, in the $2^{\text {nd }}$ week and further study period also showed a significant reduction $(\mathrm{P}<0.001)$ during $4^{\text {th }}-8^{\text {th }}$ week as compared to the normal saline group. Diabetic rats supplemented with TGME at a dose of 500mg. $\mathrm{kg}^{-1}$ (for 14 days) resulted in significant increased $(\mathrm{P}<0.001)$ latency of tail flick or struggle response compared to diabetic control group Figure 6.

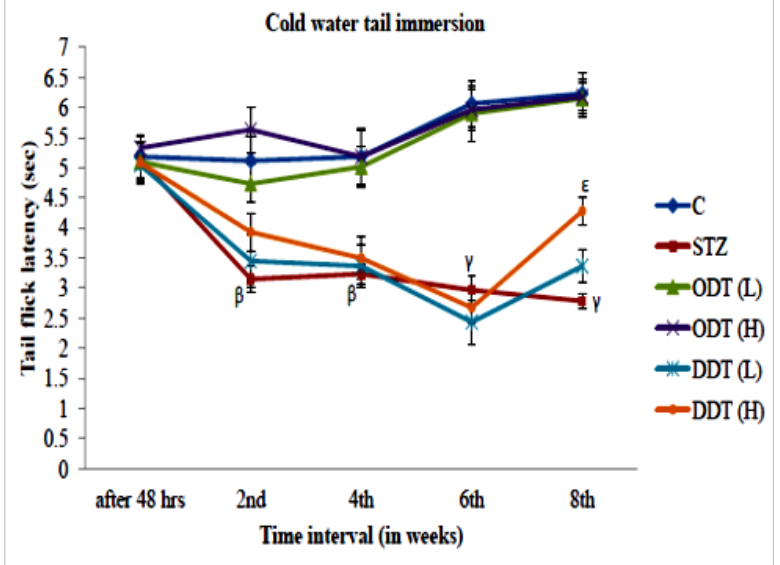

Figure 5 Effect of TGME at dose 250 and $500 \mathrm{mg} \cdot \mathrm{kg}^{-1}$ on tail flick latency in cold water tail immersion of normal and diabetic rats. Values are expressed as Mean \pm SEM $(n=6),{ }^{\beta} \mathrm{P}<0.0 \mathrm{I},{ }^{\gamma} \mathrm{P}<0.00 \mathrm{IV}$ s. Normal control group, ${ }^{\varepsilon} \mathrm{P}<0.0 \mathrm{IVs}$ Diabetic control group. One Way ANOVA followed by tukey's test for multiple comparisons.

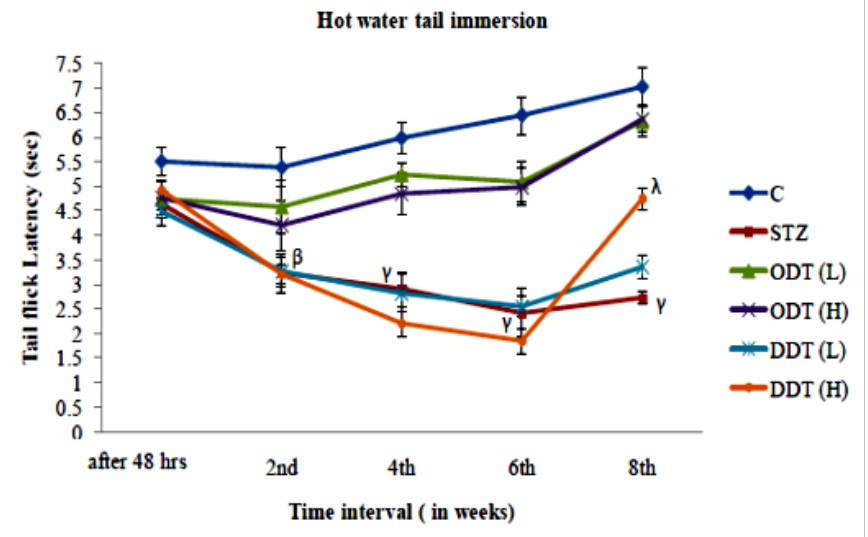

Figure 6 Effect of TGME at dose 250 and $500 \mathrm{mg} \cdot \mathrm{kg}^{-1}$ on tail flick latency in hot water tail immersion of normal and diabetic rats. Values are expressed as Mean \pm SEM $(n=6),{ }^{\beta} \mathrm{P}<0.0 \mathrm{I},{ }^{\gamma} \mathrm{P}<0.00 \mathrm{I} \mathrm{Vs}$ Control group, ${ }^{\lambda} \mathrm{P}<0.00 \mathrm{I} \mathrm{Vs} \mathrm{STZ}$ group. One Way ANOVA followed by tukey's test for multiple comparisons.

Effect of methanolic extract of Tectona grandis leaves (TGME) on lipid peroxidation and oxidative stress level in brain

After 8 weeks of STZ injection, diabetic control rats had a significantly higher $(\mathrm{P}<0.001)$ TBARS level in brain compared to normal saline control rats. However, administration of TGME at dose of 250 and $500 \mathrm{mg} \cdot \mathrm{kg}^{-1}$ significantly reduced $(\mathrm{P}<0.001)$ TBARS level in brain of diabetic rats as compared to diabetic control rats. Diabetic control rats had significantly lower $(\mathrm{P}<0.001)$ reduced GSH level in the brain compared to normal saline control rats. Administration of TGME to diabetic rats significantly improved $(\mathrm{P}<0.001)$ the reduced GSH level of brain, at both the doses (250 and $500 \mathrm{mg}^{\mathrm{kg}} \mathrm{kg}^{-1}$ p.o.) when compared to diabetic control group. Administration of STZ i.p. resulted in significant decrease $(\mathrm{P}<0.001)$ in SOD level in brain of diabetic (STZ) control rats compared to normal saline rats. SOD level in diabetic rats treated with TGME (250 and 500mg.kg-1 p.o. for 14 days) was increased significantly $(\mathrm{P}<0.001)$ and dose-dependently as compared to diabetic control group. STZ treated diabetic control group had a significantly lower $(\mathrm{P}<0.001)$ CAT level in the brain as 
compared to normal saline-treated rats. TGME at dose of 250 and $500 \mathrm{mg} \cdot \mathrm{kg}^{-1}$ p.o. (14 days) significantly increased $(\mathrm{P}<0.001)$ CAT level in brain in diabetic rats as compared to diabetic control rats Table1. Values are represented as mean $\pm \operatorname{SEM}(\mathrm{n}=6)$

Table I Effect of TGME at dose 250 and $500 \mathrm{mg} \cdot \mathrm{kg}^{-1}$ on the oxidative stress and antioxidative parameters in brain of normal and diabetic rats

\begin{tabular}{|c|c|c|c|c|}
\hline \multirow[b]{2}{*}{ Study groups } & \multicolumn{2}{|c|}{ Oxidative stress and antioxidant enzymes } & \multirow[b]{2}{*}{$\begin{array}{l}\text { SOD }\left(\mathbf{U} \mathrm{mg}^{-1} \text { of }\right. \\
\text { protein) }\end{array}$} & \multirow[b]{2}{*}{$\begin{array}{l}\text { LPO (nM MDA } \mathrm{mg}^{-1} \text { of } \\
\text { protein) }\end{array}$} \\
\hline & $\begin{array}{l}\text { GSH ( } \mu \text { M mg- I of } \\
\text { protein) }\end{array}$ & $\begin{array}{l}\text { CAT ( } \mathrm{nM} \mathrm{mg} \mathrm{mg}^{-1} \text { of } \\
\text { protein } / \mathrm{min})\end{array}$ & & \\
\hline C & $19.59 \pm 0.570$ & $4.201 \pm 0.027$ & $7.342 \pm 0.023$ & $1.389 \pm 0.126$ \\
\hline STZ & $5.11 \mathrm{II} \pm 0.484 \gamma$ & $1.423 \pm 0.074 \gamma$ & $6.396 \pm 0.066 \gamma$ & $20.99 \pm 1.248 \gamma$ \\
\hline ODT (L) & $|8.48 \pm 0.60|$ & $4.111 \pm 0.088$ & $7.234 \pm 0.039$ & $1.145 \pm 0.134$ \\
\hline ODT $(\mathrm{H})$ & $18.60 \pm 0.693$ & $4.137 \pm 0.087$ & $7.325 \pm 0.022$ & $1.123 \pm 0.105$ \\
\hline DDT (L) & $9.60 I \pm 0.617 \lambda$ & $2.385 \pm 0.057 \lambda$ & $6.773 \pm 0.079 \lambda$ & $13.56 \pm 0.642 \lambda$ \\
\hline DDT $(\mathrm{H})$ & $12.58 \pm 0.570 \lambda$ & $2.530 \pm 0.079 \lambda$ & $6.86 \mathrm{I} \pm 0.074 \lambda$ & $9.338 \pm 0.529 \lambda$ \\
\hline
\end{tabular}

Values are represented as mean \pm sem $(n=6)$

$\gamma p<0.00$ I vs control group, $\lambda p<0.00$ I vs stz group

One way anova followed by tukey's multiple comparison test

Effect of methanolic extract of Tectona grandis leaves (TGME) on the epidermal thickness of the plantar surface of the hind paw skin in diabetic rats

In normal control rat (A) showing the normal boundary between the epidermis (e) and dermis (d) is marked by a line, layer of keratinocytes (k) an outer surface; diabetic control rat (B) remarkably decrease the thickness of epidermis in diabetic control as compared to the normal control animal. Diabetic rat treated with low dose $\left(250 \mathrm{mg} \cdot \mathrm{kg}^{-1}\right)$ of TGME (C) slightly increased the boundary between the epidermis (e) and dermis (d) is marked by a line, layer of keratinocytes (k) an outer surface; and diabetic rat treated with high dose $\left(500 \mathrm{mg} \cdot \mathrm{kg}^{-1}\right)$ of TGME (D) appear normal thickness of epidermis have equal to normal saline treated rat Figure 7.

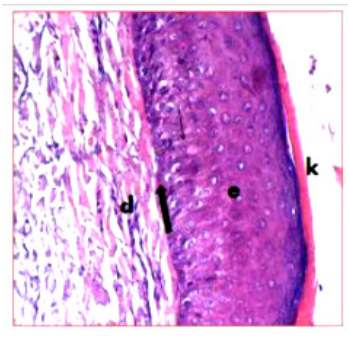

A

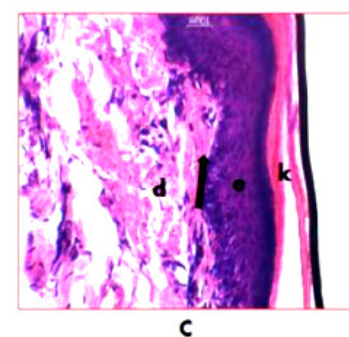

c

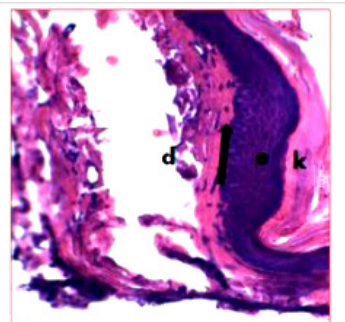

B

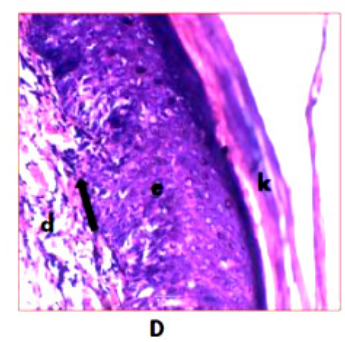

Figure 7 Effect of TGME on epidermal thickness of planter surface of the hind paw skin in diabetic rats.

\section{Discussion}

The plant under investigation (TG) revealed that it has antidiabetic, hypolipidemic, analgesic activity and also have antioxidant activity

(in-vitro and in-vivo). The literature review also supported that the leaves of this plant possess a compound, tectone which have antihyperglycaemic activity equivalent to that of metformin. ${ }^{24}$ All these activities suggested that the plant TG may have the potential to ameliorate the increased glucose, lipid level and oxidative stress in diabetic neuropathy. The pharmacognostic study supported that the TGME resulted in presence of flavonoid and tannin content in during the phytochemical screening. The estimation of total phenolic and flavonoid content resulted in highest content in the methanolic extract suggesting that antioxidant activity of the plant. ${ }^{25}$ Flavonoids act as scavengers oxidizing species they also act as quenchers of singlet oxygen. ${ }^{26}$ The extract also exhibited well in vitro antioxidant activity by DPPH and reducing power assay. The antioxidant activity of the plant is attributed to their redox properties, which allow them to act as free radical scavengers. ${ }^{27}$ The diabetic neuropathy is still one of the unmet challenges. Streptozotocin (STZ) has been widely used to induce type 1 diabetes in animal especially rats and mice. ${ }^{28}$ The STZ induced diabetic rat is the most commonly employed animal model of painful diabetic neuropathy because of similar clinicopathological symptoms exhibited by them including oxidative stress and metabolic changes. ${ }^{29,30}$ Administration of STZ to rats caused an abnormally high level of glucose, triglycerides and total cholesterol in the serum of diabetic rats compared to saline control as previously reported studies. ${ }^{31}$ In the present investigation, the glucose level was abnormally increased $(80.65 \%)$ in STZ treated rats in $8^{\text {th }}$ week, drug treatment for 14 days $\left(7^{\text {th }} \& 8^{\text {th }}\right.$ weeks), resulted in decrease of glucose level $(42.22 \%)$ and $(46.42 \%)$ at dose of 250 and $500 \mathrm{mg} . \mathrm{kg}^{-1}$ respectively in normal rats. However, drug treatment in diabetic rats for the same time period resulted in decreasing the glucose level $(35.71 \%)$ and $(45.94 \%)$ at the dose of 250 and $500 \mathrm{mg} \cdot \mathrm{kg}^{-1}$ respectively. Hyperlipidemia due to high serum triglyceride and total cholesterol concentration has been reported in diabetic and hypertensive patients. ${ }^{32}$ It is evident from our study that the level of cholesterol in STZ treated group raises after six weeks of STZ administration, TGME treatment for 14 days $\left(7^{\text {th }}\right.$ and $8^{\text {th }}$ week) resulted in significant lowering $(9.52 \%)$ and $(14.15 \%)$ of the cholesterol level in diabetic groups at a dose of 250 and $500 \mathrm{mg} \cdot \mathrm{kg}^{-1}$ respectively. The serum triglyceride level was found to be higher in diabetic group after $48 \mathrm{hrs}$ of STZ given, and TGME administration (14 days) lowered the triglyceride level in normal rats $(25.64 \%)$ and diabetic rats (14.36\%) at a dose of 500mg. $\mathrm{kg}^{-1}$ suggesting that the plant also possess hypolipidemic property in addition to hypoglycaemic. 
Administration of STZ cause lowered $\mathrm{Na}+\mathrm{K}+\mathrm{ATPase}$ activity as supported by previous studies. This lowered activity leads to altered neuronal function along with lowered antioxidant level. The nociceptive threshold was significantly lower in the diabetic rats. The nociceptive stimuli started with sensory receptors in the skin with unmyelinated sensory nerves terminal in the epidermis. In diabetic animals decrease in epidermal thickness that makes nerve fibers are more prominent at the surface of the skin and increased pain perception in. ${ }^{33}$ In the present study, we had observed that diabetic rats show cold allodynia and thermal hyperalgesia in by cold and hot water tail immersion test respectively after $2^{\text {nd }}$ week of STZ administration. The withdrawal threshold decreases in both the tests with the duration of diabetes. Results of tail flick latency suggested that after treatment with TGME for 2 weeks ( $7^{\text {th }}$ and $8^{\text {th }}$ week after STZ administration) at a dose of 500 mg. $\mathrm{kg}^{-1}$ in diabetic group, there is significant increase in nociceptive threshold by cold water immersion $(29.15 \%)$ and by hot water immersion $(57.65 \%)$ as compared with the diabetic control rats. The current study indicates that diabetic control rat exhibit a decrease in epidermal thickness of paw skin and thus reduction in epidermal nerve fibers compared to control saline rats. The diabetic rats showed a thinner skin as compared to control saline animal. This could be due to reason that the epidermal fibers are more located on the surface when thinning of the skin in diabetic animals occurs. The histopathological study demonstrates that thickness of epidermis significantly increased in a diabetic rat treated with TGME at a dose of $500 \mathrm{mg} \cdot \mathrm{kg}^{-1}$. These findings supported our study that increased epidermal thickness was responsible for the decrease of pain perception after treatment with TGME at the dose of 500mg. $\mathrm{kg}^{-1}$ in cold and hot water tail immersion tests. Chronic hyperglycemia causes oxidative stress in tissues prone to complications in patients with diabetes. ${ }^{34}$ Persistent hyperglycemia leads to the generation of free radicals causing an imbalance in the oxidative status of the nervous tissue and damage in the brain through a peroxidative mechanism. ${ }^{35}$ Studies demonstrate that the brain contains the comparatively high concentration of easily peroxidizable fatty acids ${ }^{36}$ It is evident from our study that there is an elevation of MDA, an index of lipid peroxidation in rats with diabetic neuropathy. Results of our study revealed that MDA level was increased $(92.78 \%)$ in the diabetic control group as compared to normal saline control group. Treatment with TGME decreased MDA level dose-dependently (35.39\%) and (52.38\%), after administration of 250 and $500 \mathrm{mg} \cdot \mathrm{kg}^{-1}$ respectively in diabetic rats as compared to diabetic control rats. Earlier studies indicated that certain regions of the brain are highly enriched in iron that is catalytically involved in the production of damaging oxygen free radical species $\left(\mathrm{OH}^{*_{-}}\right) .^{37}$ Exposure of brain to oxidative stress induced by oxygen free radicals seems to be due to the fact that, decreased activities of CAT and SOD may be a response to increased production of $\mathrm{H}_{2} \mathrm{O}_{2}$ and $\mathrm{O}_{2}$ by the autoxidation of glucose and nonenzymatic glycation. ${ }^{38}$ Induction of diabetic neuropathy in the present study resulted in a reduction of GSH, CAT, and SOD in the brain of diabetic control animals as compared with the saline control group. Findings of our study revealed that there decreased in glutathione (72.64\%), SOD (12.88\%) and CAT (66.12\%) in the diabetic control group as compared to normal saline control group. The level of all the above parameters were increased GSH $(48.15 \%)$ and $(57.45 \%)$, SOD $(5.56 \%)$ and $(6.86 \%)$, CAT $(39.70 \%)$ and $(43.75 \%)$ in the brain of the diabetic rats after 14 days treatment with TGME at dose of 250 and $500 \mathrm{mg} \cdot \mathrm{kg}^{-1}$ respectively as compared to diabetic control group. The increased GSH, SOD, and CAT may be a factor responsible for inhibition of lipid peroxidation.

\section{Conclusion}

It may be concluded from our study that TGME possesses potential to combat glucose by either increasing the utilization of glucose in muscles or increasing capability of intact $\beta$-cells to produce insulin; the hypolipidemic effect of TGME suggests its role in preventing diabetes-related complications. Continual hyperglycemia increased the susceptibility of the brain to oxidative stress and increasing pain perceptions by decreasing epidermal nerve fibers. Antioxidant potential of TGME exerted a beneficial action against pathologic alterations caused by the presence of free radicals in STZ diabetes via decreasing the LPO level and increasing the concentration of GSH, SOD, and CAT along with increasing thickness of the epidermis. Thus, indicating that that plant has the potential to scavenge free radicals in diseases associated with oxidative stress. Further study is required to isolate the active constituent responsible for improving the antioxidant defense in diabetic neuropathy.

\section{Acknowledgments}

Authors are thankful to the management committee of ASBASJS Memorial College of Pharmacy BELA (Ropar) for providing facilities to conduct the project.

\section{Conflict of interest}

Author declares that there is no conflict of interest.

\section{References}

1. Huizinga MM, Rothman RL. Addressing the diabetes pandemic: A comprehensive approach. Indian J Med Res. 2006;124(5):481-484.

2. Mohan V, Sandeep S, Deepa R, et al. Epidemiology of type 2 diabetes: Indian Scenario. Indian J Med Res. 2007;125(3):217-230.

3. Boulton AJ, Malik RA, Arezzo JC, et al. Diabetic somatic neuropathies. Diabetes Care. 2004;27(6):1458-1486.

4. Vinik AI. Advances in diabetes for the millennium: new treatments for diabetic neuropathies. Med Gen Med. 2004;6(3):1-13.

5. Boulton AJ, VinikAI, Arezzo JC, et al. Diabetic neuropathies: a statement by the American Diabetes Association. Diabetes Care. 2005;28(4):956-962.

6. Venkatesh S, Reddy GD, Reddy BM, et al. Antihyperglycemic activity of Caralluma attenuata. Fitoterapia. 2003;74(3):274-279.

7. Mukherjee PK, Maiti K, Mukherjee K, et al. Leads from Indian medicinal plants with hypoglycemic potentials. $J$ Ethnopharmacol. 2006;106(1):1-28.

8. Kirtikar KR, Basu BD. Indian Medicinal Plants, 4th ed. International Book Distributors, Dehradun. 1975;1924-1926.

9. Majumdar M, Nayeem N, Kamath JV, et al. Evaluation of Tectona grandis leaves for wound healing activity. Pak J Pharm Sci. 2007;20(2):120-124.

10. Goswami DV, Nirmal SA, Patil MJ, et al. An overview of Tectona grandis: Chemistry and Pharmacological profile. Pharmacog Rev. 2009;3(5):181-185.

11. Nadkarni KM, Nadkarni AK, Indian Materia Medica. 3rd ed. Popular Prakasan, Bombay. 2000;1197-1198.

12. Ghaisas MM, Navghare VV, Takawale AR, et al. Antidiabetic and nephroprotective effect of Tectona grandis linn in alloxan induced diabetes. Ars Pharm. 2010;51(4):195-206. 
13. Verma P, Sharma V, Samanta KC. Hypoglycemic activity of methanolic extract of Tectona grandis linn. Root in alloxan induced diabetic rats. $J$ Appl Pharm Sci. 2011;1(4):106-109.

14. Naira N, Karvekar. Analgesic and anti-inflammatory activity of the methanolic extract of the frontal leaves of Tectona grandis. The Internet Journal of Pharmacology. 2010;8(1):221-225.

15. Kushwah AS, Kaur P, Singh R. In-vitro antioxidant potential and phytochemical screening of Tectona grandis Linn. leaves. Int J Pharm Med Res. 2013;1(1):33-38.

16. Chopra K, Kuhad A. Tocotrienol attenuates oxidative-nitrosative stress and inflammatory cascade in experimental model of diabetic neuropathy. Neuropharmacology. 2009;57(4):456-462

17. Attal N, Jazat F, Kayser V, et al. Further evidence for 'pain-related' behaviours in a model of unilateral peripheral mononeuropathy. Pain. 1990;41(2):235-251.

18. Yalcin I, Charlet A, Freund-Mercier MJ, et al. Differentiating thermal allodynia and hyperalgesia using dynamic hot and cold plate in rodents. $J$ Pain. 2009;10(7):767-773.

19. Ohkawa H, Onishi N, Yagi K. Assay for lipid peroxidation in animal tissue by thiobarbituric acid reaction. Anal Biochem. 1979;95(2):351-358.

20.Ellman GL. Tissue sulphydryl groups. Arch Biochem Biophys. 1959;82(1):70-77.

21. Kakkar P, Das B, Viswanathan PN. A modified spectrophotometric assay of superoxide dismutase. Ind J Biochem Biophys. 1984;21(2):131-132.

22. Aebi H. Catalase. In: Bergmeyer HV, Methods in enzymatic analysis Vol 2. New york. 1974;674-684.

23. Lowry OH, Rosebrough NJ, Farr AL, et al. Protein measurement with the folin-phenol reagent. J Biol Chem. 1951;193(1):265-275.

24. Shukla N, Kumar M, Akanksha, et al. Tectone, a New Antihyperglycemic Anthraquinone from Tectona grandis Leaves. Nat Prod Commun. 2010;5(3):427-430.

25. Nabavi SM, Ebrahimzadeh MA, Nabavi SF, et al. In vitro antioxidant and free radical scavenging activity of Diospyros lotus and Pyrus boissieriana growing in Iran. Pharmacogn Mag. 2009;18(5):122-126.

26. Das N, Pereira TA. Effects of flavonoids on thermal autoxidation of palm oil: structure activity relationships. J Am Oil Chem Soc. 1990;67(4):255-258.
27. Maritim AC, Sanders RA, Watkins JB. Diabetes, oxidative stress, and antioxidants: a review. J Biochem Mol Toxicol. 2003;17(1):24-38.

28. Hayashi K, Kojima R, Ito M. Strain differences in the diabetogenic activity of streptozotocin in mice. Biol Pharmaceut Bull. 2006;29(6):1110-1119.

29. Hoybergs YM, Biermans RL, Meert TF. The impact of bodyweight and body condition on behavioral testing for painful diabetic neuropathy in the streptozotocin rat model. Neurosci Lett. 2008;43(6):13-18.

30. Dobretsov M, Hastings SL, Romanovsky D, et al. Mechanical hyperalgesia in rat models of systemic and local hyperglycemia. Brain Res. 2003;960(3):174-183.

31. Mir SH, Baqui A, Bhagat RC, et al. Biochemical and histological study of streptozotocin-induced diabetes mellitus in rabbits. Pak J Nutr. 2008;7(2):359-364.

32. Nikkila EA. Plasma triglycerides in human diabetes. Proc $R$ Soc Med. 1974;67(7):662-665

33. Hirai A, Yasuda H, Joko M, et al. Evaluation of diabetic neuropathy through the quantitation of cutaneous nerves. J Neurol Sci. 2000;172(1):55-62.

34. Rosen P, Nawroth P, King G, et al. The role of oxidative stress in the onset and progression of diabetes and its complications: a summary of a Congress Series sponsored by UNESCO-MCBN, the American Diabetes Association and the German Diabetes Society. Diabetes Metab Res Rev. 2001;17(3):189-212.

35. Baynes JW, Thrope SR. Role of oxidative stress in diabetic complications. Diabetes. 1999;48(1):1-9.

36. Carney JM, Strake-Reed PE, Oliver CN, et al. Reversal of age-related increase in brain protein oxidation, decrease in enzyme activity and loss in temporal and spatial memory by chronic administration of the spin trapping compound N-tert-butyl-alfa-phenynitrone. Proc Nat Acad Sci. 1991;88(9):3633-3636.

37. Nistico G, Cirilol HR, Fiskin K, et al. NGF restores decrease in catalas activity and increases superoxide dismutase and glutathione peroxidase activity in the brain of aged rats. Free Radic Biol Med. 1992;12(3):177-181.

38. Pari L, Latha M. Protective role of Scoparia dulcis plant extract on brain antioxidant status and lipidperoxidation in STZ diabetic male Wistar rats. Complement Altern Med. 2004;16(4):1-8. 